\title{
Milnacipran for Attention-Deficit Hyperactivity Disorder Symptoms in Adult Asperger's Disorder
}

\author{
Hirobumi Mashiko*, Hiromichi Ishikawa, Shuntaro Itagaki, Yasuko Takanashi, \\ Norihiro Miyashita, Takaaki Okano, Shin-Ichi Niwa, Hirooki Yabe \\ Department of Neuropsychiatry, School of Medicine, Fukushima Medical University, Fukushima City, Japan \\ Email: ${ }^{*}$ mashiko@fmu.ac.jp
}

Received 20 May 2014; revised 15 June 2014; accepted 10 July 2014

Copyright (C) 2014 by authors and Scientific Research Publishing Inc. This work is licensed under the Creative Commons Attribution International License (CC BY). http://creativecommons.org/licenses/by/4.0/

\begin{abstract}
The efficacy of milnacipran for the treatment of ADHD symptoms in adult Asperger's disorder patients was examined. Fifteen consecutive adult Asperger's disorder patients with ADHD symptoms were treated with milnacipran for 8 weeks. Global Assessment of Functioning (GAF) and Conners' Adult ADHD Rating Scales Objective Screening Version (CAARS-O-SV) were used for the assessment. The mean GAF scores in the 15 patients improved significantly. Inattention, inattention + hyperactivity/impulsivity and ADHD index in CAARS-0-SV were also significantly improved. Milnacipran might be useful for ADHD symptoms, exerting its effects by increasing serotonin and noradrenaline activities in Asperger's disorder.
\end{abstract}

\section{Keywords}

Milnacipran, ADHD, Asperger's Disorder

\section{Introduction}

The diagnostic and statistical manual of mental disorders, fourth edition, text revision (DSM-IV-TR) [1] gives priority to the diagnosis of pervasive developmental disorder (PDD) over that of attention-deficit hyperactivity disorder (ADHD); that is, the exclusion of PDD is necessary before diagnosing ADHD. Therefore, although ADHD symptoms without PDD have been studied extensively, little attention has been paid to PDD patients with ADHD symptoms.

Methylphenidate, an agent used for the treatment of ADHD, improves ADHD symptoms particularly, inatten-

"Corresponding author.

How to cite this paper: Mashiko, H., Ishikawa, H., Itagaki, S., Takanashi, Y., Miyashita, N., Okano, T., Niwa, S.-I. and Yabe, H. (2014) Milnacipran for Attention-Deficit Hyperactivity Disorder Symptoms in Adult Asperger's Disorder. Open Journal of Psychiatry, 4, 195-201. http://dx.doi.org/10.4236/ojpsych.2014.43026 
tion by increasing noradrenaline activity in the brain [2]-[5]. Double-blind controlled studies of methylphenidate for autism have also indicated that methylphenidate therapy improves ADHD symptoms in a proportion of patients. However, it appears that adverse effects of this drug occur more frequently in patients with PDD than in those solely with ADHD symptoms; therefore, PDD patients may not be able to tolerate higher doses [2]-[4] [6]. However, selective serotonin reuptake inhibitors (SSRIs) activate the serotonergic nervous system via the inhibition of serotonin reuptake to improve the symptoms of patients with Asperger's disorder [7]. Therefore, serotonin-noradrenaline reuptake inhibitors (SNRIs) possibly improve the symptoms of both ADHD and autism in patients with Asperger's disorder.

Although there are numerous reports of clinical experience with the SNRI venlafaxine in patients with ADHD and Asperger's disorder [6] [8]-[29], the use of milnacipran, another SNRI that is available in Japan for the treatment of ADHD and Asperger's disorder, has not been systematically reported.

In addition, whether the response of PDD patients to therapy depends on the ADHD symptom subtype has yet to be examined. Further research is required to establish drug treatments effective against the ADHD symptoms in patients with PDD [14] [19] [30].

In the present study, we compared the clinical characteristics of responders and non-responders to milnacipran therapy among ADHD patients. The distinction between the responders and non-responders was determined according to whether social functioning improved or not. In addition, we aimed to distinguish the specific ADHD symptoms that contributed significantly to the improvement of social functioning. We exclusively selected patients without intellectual or language problems for this study in order to make the symptom evaluation as precise as possible. Therefore, we concentrated on Asperger's disorder among other pervasive developmental disorders.

\section{Subjects and Methods}

Fifteen consecutive adult Asperger's disorder patients who had ADHD symptoms diagnosed according to the DSM-IV-TR, except for criterion E, were treated with milnacipran. None of the patients had mental retardation.

The assessment of social functioning was conducted using the Global Assessment of Functioning (GAF). GAF scores were determined before and 12 weeks after milnacipran.

The DSM-IV-TR does not provide criteria for the coexistence of ADHD and Asperger's disorder. According to the DSM-IV-TR criteria, the diagnosis of Asperger's disorder takes priority over the diagnosis of ADHD [31]. In the present study, we attempted to determine the specific ADHD symptoms in patients with Asperger's disorder. Therefore, we examined ADHD symptoms associated with Asperger's disorder.

\subsection{Subjects}

This study included consecutive 15 patients with Asperger's disorder (DSM-IV-TR) who visited the outpatient clinic of the Department of Neuropsychiatry at Fukushima Medical University Hospital; they were diagnosed as having ADHD symptoms according to the DSM-IV-TR criteria except for criterion E (Table 1). The lead author of this report was solely responsible for diagnosing. The subjects consisted of 7 men and 8 women with the mean age \pm standard deviation age of $30.40 \pm 7.63$ years (range, 19 - 49 years). Written informed consent was obtained from all subjects prior to participation.

\subsection{Dosing Schedule}

Milnacipran was prescribed within the dose ranges used in common clinical practice. Dose of methylphenidate administered prior to milnacipran remained unchanged during milnacipran administration.

\subsection{Symptom and Function Evaluation}

GAF scores were determined before and 12 weeks after milnacipran. The symptoms were assessed with Conners' Adult ADHD Rating Scales-Objective-Screening Version (CAARS-O-SV) [32]. One of the coauthors (SI) purchased CAARS-O-SV from the commercial source.

\subsection{Statistical Analysis}

ANOVA was performed, being GAF scores/CAARS scores as the dependent variables and milnacipran/me- 
Table 1. Demographics of GAF and CAARS-O-SV before and after Milnacipran $(\mathrm{N}=15)$.

\begin{tabular}{|c|c|c|c|c|c|c|c|c|c|c|c|c|c|c|}
\hline \multirow{3}{*}{$\begin{array}{l}\text { Entry } \\
\text { Order }\end{array}$} & \multirow{3}{*}{ Age } & \multirow{3}{*}{ Gender } & \multirow{2}{*}{\multicolumn{2}{|c|}{ GAF }} & \multicolumn{8}{|c|}{ CAARS-0-SV } & \multirow{3}{*}{$\begin{array}{c}\text { MIL } \\
\text { (mg/day) }\end{array}$} & \multirow{3}{*}{$\begin{array}{c}\text { MPH } \\
\text { (mg/day) }\end{array}$} \\
\hline & & & & & \multicolumn{2}{|c|}{ A } & \multicolumn{2}{|c|}{ B } & \multicolumn{2}{|c|}{$\mathrm{C}$} & \multicolumn{2}{|c|}{ D } & & \\
\hline & & & before & after & before & after & before & after & before & after & before & after & & \\
\hline 1 & 38 & M & 50 & 60 & 69 & 52 & 40 & 40 & 55 & 46 & 72 & 53 & 100 & 0 \\
\hline 2 & 35 & M & 55 & 75 & 52 & 52 & 40 & 40 & 46 & 46 & 72 & 53 & 75 & 40 \\
\hline 3 & 24 & $\mathrm{~F}$ & 35 & 60 & 54 & 54 & 48 & 42 & 52 & 48 & 75 & 54 & 75 & 0 \\
\hline 4 & 49 & $\mathrm{~F}$ & 35 & 55 & 90 & 73 & 44 & 44 & 70 & 60 & 78 & 57 & 150 & 0 \\
\hline 5 & 21 & $\mathrm{M}$ & 55 & 70 & 69 & 52 & 35 & 35 & 52 & 43 & 88 & 70 & 120 & 30 \\
\hline 6 & 30 & $\mathrm{~F}$ & 50 & 70 & 84 & 54 & 60 & 48 & 77 & 52 & 55 & 55 & 75 & 20 \\
\hline 7 & 29 & M & 45 & 55 & 85 & 52 & 35 & 35 & 62 & 43 & 70 & 51 & 195 & 30 \\
\hline 8 & 29 & F & 45 & 65 & 69 & 54 & 36 & 36 & 55 & 45 & 75 & 54 & 120 & 20 \\
\hline 9 & 19 & $\mathrm{~F}$ & 30 & 50 & 84 & 54 & 36 & 36 & 65 & 45 & 75 & 54 & 100 & 8 \\
\hline 10 & 26 & $\mathrm{~F}$ & 40 & 55 & 69 & 54 & 48 & 48 & 61 & 52 & 75 & 54 & 150 & 20 \\
\hline 11 & 35 & $\mathrm{M}$ & 40 & 65 & 52 & 52 & 52 & 52 & 52 & 52 & 90 & 53 & 225 & 0 \\
\hline 12 & 31 & $\mathrm{~F}$ & 40 & 65 & 84 & 54 & 38 & 38 & 65 & 45 & 76 & 55 & 15 & 20 \\
\hline 13 & 23 & $\mathrm{M}$ & 40 & 80 & 85 & 52 & 35 & 35 & 62 & 43 & 70 & 51 & 50 & 40 \\
\hline 14 & 36 & F & 60 & 80 & 69 & 39 & 38 & 38 & 55 & 36 & 76 & 55 & 75 & 0 \\
\hline 15 & 31 & M & 40 & 70 & 85 & 36 & 58 & 52 & 74 & 43 & 72 & 53 & 30 & 20 \\
\hline
\end{tabular}

GAF: Global Assessment of Functioning; CAARS-O-SV: Conner’s Adult ADHD Rating Scales ScreeningVersion; MIL: milnacipran; MPH: methylphenidate.

thylphenidate as the factors. In order to determine the relationship between the changes in GAF scores and changes in clinical symptoms, multiple regression analysis was performed using "changes in GAF scores (difference from baseline)" ( $N=15)$ as the dependent variable. Multiple regression analysis involved symptom assessment focusing on "inattention”, "hyperactivity", "impulsivity” and "ADHD index".

\section{Results}

Among the 15 patients (Table 1), 5 received milnacipran monotherapy, and 10 received combined milnacipran and methylphenidate therapy. The mean \pm SD doses of milnacipran and methylphenidate were $103.67 \pm 58.17$ (range, 15 - 225; $\mathrm{N}=15$ ) $\mathrm{mg} /$ day and $16.53 \pm 14.55$ (range 8 - 40; $\mathrm{N}=10$ ) mg/day, respectively.

\subsection{Changes in GAF Scores and CAARS-0-SV Scores after Milnacipran (Table 2)}

The changes in social functioning as assessed by GAF scores with treatment were examined. The GAF score (mean $\pm \mathrm{SD}$ ) in the 15 patients improved significantly from $44.00 \pm 8.49$ before therapy $(\mathrm{N}=15)$ to $65.00 \pm 9.26$ after milnacipran $(\mathrm{F}=33.89, \mathrm{df}=1, p<0.001)$.

\subsection{Changes in Social Functioning and Clinical Symptoms with Respect to the Presence or Absence of Methylphenidate (Table 3)}

Analysis of variance (ANOVA) using GAF scores and CAARS-O-SV scores as the independent variables was performed employing "before/after milnacipran" and "with/without methylphenidate" as the factors. As a result, significant effects of "before/after milnacipran" were observed on GAF, inattention, inattention + hyperactivity/ impulsivity and ADHD index $(\mathrm{F}=33.89, \mathrm{df}=1, p<0.001 ; \mathrm{F}=21.20, \mathrm{df}=1, p<0.001 ; \mathrm{F}=18.25, \mathrm{df}=1, p<$ $0.001 ; \mathrm{F}=70.64, \mathrm{df}=16, p<0.001$; respectively). No significant effects of "before/after milnacipran" were observed on hyperactivity/impulsivity. Moreover, no significant effects of "with/without methylphenidate" were 
Table 2. GAF and CAARS-O-SV before and after Milnacipran ( $=15)$.

\begin{tabular}{lcc}
\hline & before MIL & after MIL \\
\hline GAF & $44 \pm 8.49$ & $65.00 \pm 9.26^{*}$ \\
CAARS-O-SV & & \\
A: inattention & $73.33 \pm 13.11$ & $52.27 \pm 7.97^{*}$ \\
B: hyperactivity, impulsiveness & $42.87 \pm 8.47$ & $41.26 \pm 6.13$ \\
C: A + B & $62.20 \pm 8.89$ & $46.60 \pm 5.62^{*}$ \\
D: ADHD index & $74.60 \pm 7.93$ & $54.80 \pm 4.48^{*}$ \\
\hline
\end{tabular}

GAF: Global Assessment of Functioning; CAARS-O-SV: Conners’ Adult ADHD Rating Scales Objective Screening Version; MIL: milnacipran; * $p<0.001$ (refer to Table 3).

Table 3. ANOVA of GAF and CAARS-0-SV before and after Milnacipran ( $\mathrm{N}=15)$.

\begin{tabular}{cccc}
\hline Dependent Variable & \multicolumn{1}{c}{ Factors } & Interaction \\
\cline { 2 - 4 } GAF & $\mathrm{MIL}$ & $\mathrm{MPH}$ & $\mathrm{MIL} * \mathrm{MPH}$ \\
CAARS-0-SV & $\mathrm{F}=33.89, \mathrm{df}=1, p<0.001$ & $\mathrm{~ns}$ & $\mathrm{~ns}$ \\
A: inattention & $\mathrm{F}=21.20, \mathrm{df}=1, p<0.001$ & $\mathrm{~ns}$ & $\mathrm{~ns}$ \\
B: hyperactivity, impulsiveness & $\mathrm{ns}$ & $\mathrm{ns}$ & $\mathrm{ns}$ \\
C: A + B & $\mathrm{F}=18.25, \mathrm{df}=1, p<0.001$ & $\mathrm{~ns}$ & $\mathrm{~ns}$ \\
D: ADHD index & $\mathrm{F}=70.64, \mathrm{df}=1, p<0.001$ & $\mathrm{~ns}$ & $\mathrm{~ns}$ \\
\hline
\end{tabular}

GAF: Global Assessment of Functioning; CAARS-O-SV: Conners’ Adult ADHD Rating Scales Screening Version; MIL: milnacipran; MPH: methylphenidate.

observed on GAF, inattention, hyperactivity/impulsivity, inattention + hyperactivity/impulsivity and ADHD index. Furthermore, no significant interactions were observed between "before/after milnacipran" and "with/ without methylphenidate".

\subsection{Relationship between Changes in Social Functioning and Changes in Clinical Symptoms}

In order to determine the relationship between changes in social functioning and changes in clinical symptoms, multiple regression analysis was performed using changes in social functioning (i.e., GAF scores) $(\mathrm{N}=15)$ as the dependent variable. "Changes in inattention", "change in hyperactivity/impulsivity", "change in inattention + hyperactivity/impulsivity" and "change in ADHD index" were chosen as the independent variables. The regression was not significant.

\section{Discussion}

\subsection{Summary of Results}

In the present study, we prescribed milnacipran to 15 adult Asperger's disorder patients with ADHD symptoms and evaluated the results of milnacipran. To our knowledge, this is the first report of clinical experience with milnacipran in adult Asperger's disorder with ADHD symptoms. The results of our study suggested that milnacipran produces improvement in social functioning in patients having ADHD symptoms associated with Asperger's disorder, particularly through improvement of inattention.

\subsection{ADHD Symptoms in Asperger's Disorder and Effects of Methylphenidate on ADHD Symptoms in Asperger's Disorder}

Recently, Gadow et al. [31] compared the clinical characteristics of ADHD associated and not associated with PDD, and reported that the ADHD symptoms was identical in both the groups. Their finding supports the existence of the ADHD symptoms in patients with PDD. As described earlier, previous reports by other authors 
demonstrated that methylphenidate exhibited efficacy for ADHD symptoms in PDD patients, and that PDD patients with ADHD symptoms were more prone to show adverse effects to methylphenidate as compared to ADHD patients without PDD symptoms. Although it is not clear why adverse effects of methylphenidate are more likely to occur in PDD patients than in ADHD patients, possible explanations include a difference in the pathophysiology between ADHD and PDD. A study on ADHD symptoms associated with Asperger's disorder by the Research Units on Pediatric Psychopharmacology (RUPP) has been performed [5].

\subsection{Comparison of Milnacipran and Methylphenidate}

Methylphenidate exerts its actions by inhibiting dopamine and noradrenaline uptake. In contrast, milnacipran exerts its effects by inhibiting noradrenaline and serotonin reuptake. Thus, while milnacipran, unlike methylphenidate, does not inhibit dopamine reuptake, it inhibits serotonin reuptake, which might be critical in the treatment of PDD. Thus, inhibition of serotonin reuptake, an action not exerted by methylphenidate, is one of the great advantages of milnacipran. Milnacipran with its action of inhibiting serotonin reuptake may be expected to be more useful than methylphenidate for improving the ADHD symptoms in patients of PDD.

\subsection{Rationale for the Use of SNRIs in the Treatment of Developmental Disorders (ADHD and Asperger's Disorder)}

Duloxetine, milnacipran, nefazodone and venlafaxine are clinically available SNRIs in the world. Although these SNRIs differ with respect to their potentials, they share inhibiting abilities of serotonin and noradrenaline reuptake. While clinical experiences of the use of venlafaxine for the treatment of ADHD and Asperger's disorder has been frequently reported, information on the clinical use of duloxetine, milnacipran and nefazodone for ADHD and Asperger's disorder is limited among the existing literature. Nefazodone is not marketed, and duloxetine commenced to be marketed in 2010 in Japan. We do not have enough experience of duloxetine in patients with developmental disorders. Therefore, we examined the effects of milnacipran for the treatment of ADHD symptoms among Asperger's disorder.

Methylphenidate, which has long been used for ADHD symptoms enhances the activity of not only dopamine but also of noradrenaline. This is consistent with the multiple lines of evidence implicating the central DA and NE systems in the pathophysiology of ADHD [33]. On the other hand, methylphenidate is speculated to improve ADHD symptoms (particularly inattention) via increasing the activity of noradrenaline in the brain [2]-[5]. In addition, the wide involvement of noradrenaline in the pathophysiology of ADHD such as inattention, hyperactivity and impulsivity is supported by the fact that atmoxetine, a selective noradrenaline re-uptake inhibitor, is appreciated as an effective agent for ADHD. Thus, the potential inhibiting ability of noradrenaline re-uptake of milnacipran is thought to underpin its effects for ADHD symptoms. Comparison of the symptoms most likely to show improvement after venlafaxine and milnacipran treatment remains to be addressed in future studies.

On the other hand, in Asperger's disorder, the improvement of the autistic symptoms might be produced via increasing the serotonin activity [18]. Serotonin is known to play critical roles in wide variety of psychic functions, namely aggression, anxiety, mood, impulsivity, sleep, eating behavior, reward system, and psychosis [34]. In particular, a growing body of evidence links autism spectrum disorders to abnormalities in serotonin function, and the selective serotonin reuptake inhibitors (SSRIs) have been utilized to various symptoms of the disorders. Therefore, the SNRI milnacipran, which enhances the activity of both serotonin and noradrenaline, may be expected to improve both ADHD symptoms and autistic symptoms in patients of Asperger's disorder [34].

Furthermore, in the present study, the multiple regression analysis of factors influencing the improvement of social functioning revealed that both "improvement of inattention" and "improvement of difficulties in interpersonal relationships" were contributory factors. This result is thought to clearly lend support to our above presumption.

\subsection{Comparison of the Adverse Effects of Milnacipran and Methylphenidate}

Milnacipran is associated with a lower incidence of adverse effects, and is thus tolerated better than tricyclic antidepressants. The summation of adverse effects from double-blind controlled studies shows that the incidence of discontinuation of therapy due to adverse effects was $7.6 \%$ for milnacipran (1871 cases) and $14.8 \%$ for tricyclic antidepressants (940 cases) [35]. In the present study, the incidence of dropout due to adverse effects of 
milnacipran was similar, that is, $6.25 \%$ (1 case). This figure is lower than the dropout rate for methylphenidate therapy (18\%) reported in the literature [5].

\section{Conclusion}

Increased serotonin and noradrenaline activities are assumed to be associated with the improvement of ADHD symptoms in Asperger's disorder. Milnacipran might exert its effect for ADHD symptoms through intensifying the activity of noradrenaline, while for Asperger's disorder symptoms through elevating the activity of serotonin.

\section{Conflict of Interests}

There are no conflicts of interest to declare.

\section{References}

[1] American Psychiatric Association (2000) Diagnostic and Statistical Manual of Mental Disorders. 4th Edition, Text Revision. American Psychiatric Press, Washington DC.

[2] Birmaher, B., Quintana, H. and Greenhill, L. (1987) Methylphenidate Treatment of Hyperactive Autistic Children. Journal of the American Academy of Child and Adolescent Psychiatry, 26, 248-251.

[3] Handen, B.L., Johnson, C.R. and Lubetsky, M. (2000) Efficacy of Methylphenidate among Children with Autism and Symptoms of Attention-Deficit Hyperactivity Disorder. Journal of Autism and Developmental Disorders, 30, 245-255. http://dx.doi.org/10.1023/A:1005548619694

[4] Quintana, H., Birmaher, B., Stedge, D., Lennon, S., Freed, J., Bridge, J. and Greenhill, L. (1995) Use of Methylphenidate in the Treatment of Children with Autistic Disorder. Journal of Autism and Developmental Disorders, 25, $283-294$. http://dx.doi.org/10.1007/BF02179289

[5] Research Units on Pediatric Psychopharmacology (RUPP) Autism Network (2005) Randomized, Controlled, Crossover Trial of Metylphenidate in Pervasive Developmental Disorders with Hyperactivity. Archives of General Psychiatry, 62, 1266-1274. http://dx.doi.org/10.1001/archpsyc.62.11.1266

[6] Tavakoli, S.A. and Gleason, O.C. (2003) Seizures Associated with Venlafaxine, Methylphenidate, and Zolpidem. Psychosomatics, 44, 262-264. http://dx.doi.org/10.1176/appi.psy.44.3.262

[7] Martin, A., Koenig, K., Anderson, G.M. and Scahill, L. (2003) Low-Dose Fluvoxamine Treatment of Children and Adolescents with Pervasive Developmental Disorders: A Prospective, Open-Label Study. Journal of Autism and Developmental Disorders, 33, 77-85. http://dx.doi.org/10.1023/A:1022234605695

[8] Adler, L.A., Resnick, S., Kunz, M. and Devinsky, O. (1995) Open-Label Trial of Venlafaxinein Adults with Attention Deficit Disorder. Psychopharmacology Bulletin, 31, 785-788.

[9] Carminati, G.G., Deriaz, N. and Bertschy, G. (2006) Low-Dose Venlafaxine in Three Adolescents and Young Adults with Autistic Disorder Improves Self-Injurious Behavior and Attention Deficit/Hyperactivity Disorders (ADHD)-Like Symptoms. Progress in Neuro-Psychopharmacologyand Biological Psychiatry, 30, 312-315.

[10] Chong, Y., Harris, R. and Kim, W.J. (1999) Dystonia as a Side Effect of Nonneuroleptics. Journal of the American Academy of Child and Adolescent Psychiatry, 38, 793-795. http://dx.doi.org/10.1097/00004583-199907000-00005

[11] Findling, R.L. and Dogin, J.W. (1998) Psychopharmacology of ADHD: Children and Adolescents. Journal of Clinical Psychiatry, 59, 42-49.

[12] Findling, R.L., Schwartz, M.A., Flannery, D.J. and Manos, M.J. (1996) Venlafaxine in Adults with Attention-Deficit/ Hyperactivity Disorder: An Open Clinical Trial. Journal of Clinical Psychiatry, 57, 184-189

[13] Hedges, D., Reimherr, F.W., Rogers, A., Strong, R. and Wender, P.H. (1995) An Open Trial of Venlafaxine in Adult Patients with Attention Deficit Hyperactivity Disorder. Psychopharmacology Bulletin, 31, 779-783.

[14] Hornig, M. (1998) Addressing Comorbidity in Adults with Attention-Deficit/Hyperactivity Disorder. Journal of Clinical Psychiatry, 59, 69-75.

[15] Hornig-Rohan, M. and Amsterdam, J.D. (2002) Venlafaxine versus Stimulant Therapy in Patients with Dual Diagnosis ADD and Depression. Progressin Neuro-Psychopharmacology and Biological Psychiatry, 26, 585-589. http://dx.doi.org/10.1016/S0278-5846(01)00312-8

[16] Kako, Y., Niwa, Y., Toyomaki, A., Yamanaka, H., Kitagawa, N., Denda, K. and Koyama, T. (2007) A Case of Adult Attention-Deficit/Hyperactivity Disorder Alleviated by Milnacipran. Progress in Neuro-Psychopharmacology and Biological Psychiatry, 31, 772-775. http://dx.doi.org/10.1016/j.pnpbp.2006.12.017 
[17] Krause, K.H., Krause, J. and Trott, G.E. (1998) [Hyperkinetic Syndrome (Attention Deficit-/Hyperactivity Disorder) in Adulthood]. Der Nervenarzt, 69, 543-556. (in German) http://dx.doi.org/10.1007/s001150050311

[18] Maidment, I.D. (2003) The Use of Antidepressants to Treat Attention Deficit Hyperactivity Disorder in Adults. Journal of Psychopharmacology, 17, 332-336. http://dx.doi.org/10.1177/02698811030173016

[19] Mukaddes, N.M. and Abali, O. (2004) Venlafaxine in Children and Adolescents with Attention Deficit Hyperactivity Disorder. Psychiatry and Clinical Neuroscience, 58, 92-95. http://dx.doi.org/10.1111/j.1440-1819.2004.01199.x

[20] Ninan, P.T. (2000) Use of Venlafaxine in Other Psychiatric Disorders. Depression and Anxiety, 12, 90-94.

[21] Olvera, R.L., Pliszka, S.R., Luh, J. and Tatum, R. (1996) An Open Trial of Venlafaxine in the Treatment of AttentionDeficit/Hyperactivity Disorder in Children and Adolescents. Journal of Child and Adolescent Psychopharmacology, 6, 241-250. http://dx.doi.org/10.1089/cap.1996.6.241

[22] Pary, R., Lewis, S., Matuschka, P.R., Rudzinskiy, P., Safi, M. and Lippmann, S. (2002) Attention Deficit Disorder in Adults. Annals of Clinical Psychiatry, 14, 105-111. http://dx.doi.org/10.3109/10401230209149097

[23] Pityaratstian, N. (2005) Advances in Alternative Pharmacotherapy of ADHD. Journal of the Medical Association of Thailand, 88, S357-S362.

[24] Pleak, R.R. and Gormly, L.J. (1995) Effects of Venlafaxine Treatment for ADHD in a Child. American Journal of Psychiatry, 152, 1099.

[25] Popper, C.W. (1997) Antidepressants in the Treatment of Attention-Deficit/Hyperactivity Disorder. Journal of Clinical Psychiatry, 58, 14-29.

[26] Popper, C.W. (2000) Pharmacologic Alternatives to Psychostimulants for the Treatment of Attention-Deficit/Hyperactivity Disorder. Child and Adolescent Psychiatric Clinics of North America, 9, 605-646.

[27] Smith, M.N. (1997) Pharmacologic Properties of Venlafaxine. Journal of Clinical Psychiatry, 58, 178-179. http://dx.doi.org/10.4088/JCP.v58n0407h

[28] Upadhyaya, H.P., Brady, K.T., Sethuraman, G., Sonne, S.C. and Malcom, R. (2001) Venlafaxine Treatment of Patients with Comorbid Alcohol/Cocaine Abuse and Attention-Deficit/Hyperactivity Disorder: A Pilot Study. Journal of Clinical Psychopharmacology, 21, 116-118. http://dx.doi.org/10.1097/00004714-200102000-00025

[29] Wilens, T.E., Biederman, J. and Spencer, T.J. (1995) Venlafaxine for Adult ADHD. American Journal of Psychiatry, 152, 1099-1100.

[30] Zepf, F.D., Holtmann, M., Stadler, C., Demisch, L., Schmitt, M., Wöckel, L. and Poustka, F. (2008) Diminished Serotonergic Functioning in Hostile Children with ADHD: Tryptophan Depletion Increases Behavioral Inhibition. Pharmacopsychiatry, 41, 60-65. http://dx.doi.org/10.1055/s-2007-1004593

[31] Gadow, K.D., DeVincent, C.J. and Pomeroy, J. (2006) ADHD Symptom Subtypes in Children with Pervasive Developmental Disorder. Journal of Autism and Development Disorders, 36, 271-283. http://dx.doi.org/10.1007/s10803-005-0060-3

[32] Conners, C.K., Erhardt, D. and Sparrow, E.P. (1999) Technical Manual. Multi-Health Systems, Inc., North Tonawanda.

[33] Minzenberg, M.J. (2012) Pharmacotherapy for Attention-Deficit/Hyperactivity Disorder: From Cells to Circuits. Neurotherapeutics, 9, 610-621. http://dx.doi.org/10.1007/s13311-012-0128-7

[34] Kolevzon, A., Mathewson, K.A. and Hollander, E. (2006) Selective Serotonin Reuptake Inhibitors in Autism: A Review of Efficacy and Tolerability. Journal of Clinical Psychiatry, 67, 407-414. http://dx.doi.org/10.4088/JCP.v67n0311

[35] Puech, A., Montgomery, S.A., Prost, J.F., Solles, A. and Briley, M. (1997) Milnacipran, a New Serotonin and Noradrenaline Reuptake Inhibitor: An Overview of Its Antidepressant Activity and Clinical Tolerability. International Clinical Psychopharmacology, 12, 99-108. http://dx.doi.org/10.1097/00004850-199703000-00005 
Scientific Research Publishing (SCIRP) is one of the largest Open Access journal publishers. It is currently publishing more than 200 open access, online, peer-reviewed journals covering a wide range of academic disciplines. SCIRP serves the worldwide academic communities and contributes to the progress and application of science with its publication.

Other selected journals from SCIRP are listed as below. Submit your manuscript to us via either submit@scirp.org or Online Submission Portal.
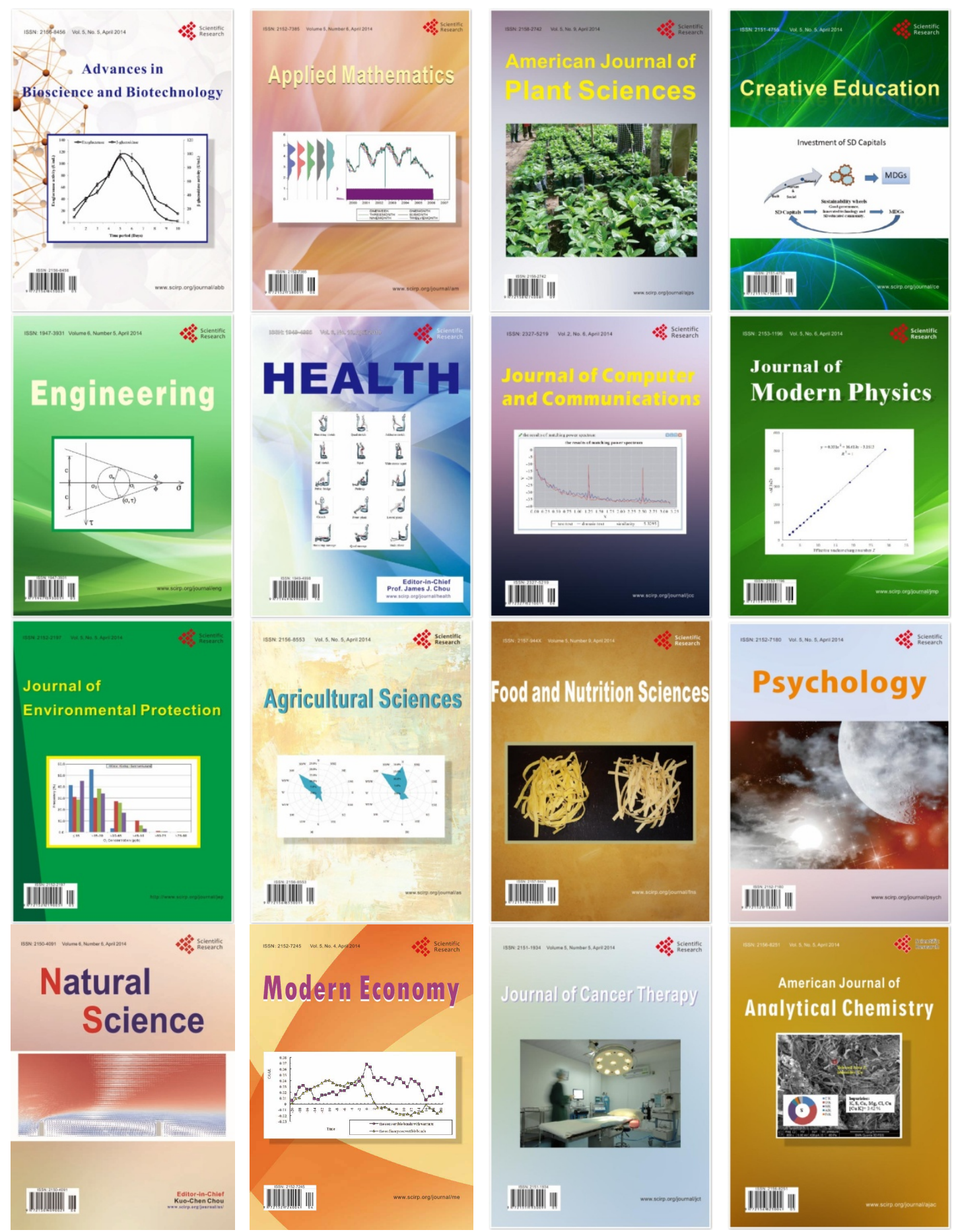